\title{
A Fault-Tolerant Control Architecture for Induction Motor Drives in Automotive Applications
}

\author{
Demba Diallo, Member, IEEE, Mohamed El Hachemi Benbouzid, Senior Member, IEEE, and Abdessalam Makouf
}

\begin{abstract}
This paper describes a fault-tolerant control system for a high-performance induction motor drive that propels an electrical vehicle $(\mathrm{EV})$ or hybrid electric vehicle (HEV). In the proposed control scheme, the developed system takes into account the controller transition smoothness in the event of sensor failure. Moreover, due to the EV or HEV requirements for sensorless operations, a practical sensorless control scheme is developed and used within the proposed fault-tolerant control system. This requires the presence of an adaptive flux observer. The speed estimator is based on the approximation of the magnetic characteristic slope of the induction motor to the mutual inductance value. Simulation results, in terms of speed and torque responses, show the effectiveness of the proposed approach.
\end{abstract}

Index Terms-Automotive application, fault-tolerant control, induction motor drive.

\section{NOMENCLATURE}

$s,(r) \quad$ Stator (rotor) index.

$d, q \quad$ Synchronous reference frame indexes.

$\alpha, \beta \quad$ Fixed stator reference frame indexes.

$V \quad$ Voltage.

$I(i) \quad$ Current.

$\varphi \quad$ Flux.

$\omega(\Omega) \quad$ Rotor speed.

$\omega_{s} \quad$ Flux synchronous speed.

$\theta_{s} \quad$ Rotor flux angular position.

$R \quad$ Resistance.

$L \quad$ Inductance.

$M \quad$ Mutual inductance.

$T_{r} \quad$ Rotor time constant $T_{r}=L_{r} / R_{r}$.

$\sigma \quad$ Total leakage coefficient $\sigma=1-M^{2} / L_{s} L_{r}$.

$\gamma \quad$ Constant $\gamma=-\left(R_{s}+M^{2} R_{r} / L_{r}^{2}\right) / \sigma L_{s}$.

$K \quad$ Constant $K=M / \sigma L_{s} L_{r}$.

$\bar{x}(\hat{x}) \quad$ Complex (estimated) value.

\section{INTRODUCTION}

OEVERAL failures can affect electrical motor drives [1]-[4] and many different remedial techniques have been proposed [5]-[10]. So far, redundant or conservative design has been used in every application where the continuity of

Manuscript received January 19, 2004; revised May 27, 2004.

D. Diallo is with the Laboratoire de Génie Electrique de Paris (LGEP), University of Paris XI, Gif-Sur-Yvette 91192, France (e-mail: ddiallo@ieee.org).

M. E. H. Benbouzid is with the Laboratoire d Ingénierie Mécanique et Electrique (LIME) ERCS UBO, Electrical Engineering Department, IUT of Brest, University of Western Brittany, 29231 Brest Cedex 3, France (e-mail: m.benbouzid@ieee.org).

A. Makouf is with the Electrical Engineering Department, University of Batna, Batna 05000, Algeria.

Digital Object Identifier 10.1109/TVT.2004.833610 operations is a key feature. Nevertheless, some applications accept short torque transients and even permanently reduced drive performance after a fault, on the condition that the drive continues to run. This is the clear case of home and civil appliances, such as, for example, air conditioning/heat pumps, engine-cooling fans, and electric vehicles. This is especially important in high-impact automotive applications such as an electrical vehicle (EV) or hybrid electric vehicle (HEV), where even limp-back operation is preferred to no operation.

For specialized applications, switch reluctance (SR) and variable reluctance (VR) permanent magnet motors are often designed to be less susceptible to various faults [11], [12]. Other papers have indicated that permanent magnet synchronous machines (PMSM) may be better suited to some of these applications [13]. However, it seems that vector-controlled induction motor drives are being increasingly used as mission critical components in high-performance automotive applications [14]. In fact, recent technological developments have pushed alternating current (ac) motors into a new era, leading to definite advantages over other motors, such as higher efficiency, higher power density, lower cost, better reliability, and next to no maintenance. As high reliability and maintenance-free operation are prime considerations in EV or HEV propulsion, induction motors are becoming attractive [15]-[17].

The most common type of $\mathrm{HEV}$ is the parallel type, in which the internal combustion engine (ICE) and the electric motor (EM) are directly connected to the wheels. This structure presents a relative advantage in control over other induction motor applications, such as servos. The advantage is that the induction motor will operate only virtually at a speed above the idle speed of the ICE. The only situation in which the EM will need to operate at a lower speed will be the transient from zero (stalled) to idle speed. This creates grounds for the use of sensorless control techniques that are known to perform well, expect for low-speed operations. However, all known speed sensorless techniques are sensitive to the parameter variations. The induction motor parameters vary with the operating conditions, as is the case with all electric motors. Furthermore, for a propulsion application, the operating conditions will vary continuously.

The study reported in this paper deals with the problem of developing an induction motor drive with a tolerance to very specific faults due to sensor failures. For fault-tolerant drives to become practical entities, both the hardware and software must be developed to perform the following tasks: fault detection; fault diagnosis; remedial action selection; and implementation. It will be necessary to act in this sequence in the shortest possible time after the occurrence of the fault, in order to prevent the 
occurrence of secondary failures. Fault tolerance has become an increasingly interesting topic in the last decade, when automation has become more complex. A trend toward more autonomic control systems also drives the interest for fault tolerance. In mass-produced industrial systems, the unit cost is a paramount issue. Hence, cheap fault-tolerant control has become an important industrial research area. The objective is to give solutions that provide fault tolerance to the most frequent faults, thereby, reducing the costs of dealing with the faults.

This paper describes the diverse nature of requirements and approaches to the fault-tolerant control of induction motor drives to be used in automotive applications. The problem here is not to discuss which technique of control to use, but how to guarantee a minimum level of performance once the drive has been submitted to a fault (e.g., subject to full or partial sensor failure). Due to this stress, our first objective is to set an automatic system that is devoted to the induction motor drive fault-tolerant control. Four control strategies are used to achieve this goal. Among these, a practical sensorless control technique is developed, which requires the presence of an adaptive flux observer. The speed estimator is based on the induction motor magnetic characteristic slope approximation to the mutual inductance value. The second objective is to obtain a smooth transition between two control techniques when a sensor failure occurs.

\section{INDUCTION MOTOR CONTROL}

Induction motor drives control techniques are well treated in the literature [18], [19]. The most popular is the so-called scalar control method. This technique allows great performances only in the steady state, because precise control of the instantaneous torque is not possible. The vector-control technique is now used for high-impact automotive applications (EV and HEV) [20]-[24]. In this case, the torque control is extended to transient states and allows better dynamic performances.

\section{A. Adopted Control Techniques}

Much discussion in the literature has focused on choosing between the various control alternatives and deciding which one to implement, depending on the requirements of the particular induction motor application. In our case, rather than developing a nominal controller based on a single control technique, the architecture developed here adaptively changes control techniques in the event of sensor loss to attain the best performance with the remaining sensors.

For high-performance induction motor drive systems over the entire speed range, indirect field-oriented controllers (IFOC) are commonly used. These controllers typically incorporate rotor position and motor current feedbacks [25].

Sensorless vector controllers eliminate the need for position feedback, but operate poorly at very low speeds [26]. This is why we have proposed a practical speed estimator, which is particularly well adapted for EV or HEV applications.

Scalar control methods have been used when rotor flux orientation cannot be maintained. However, they do not allow decoupled torque and flux control [27].
A Volts/Hertz open-loop induction motor can be used without feedback sensors. This, however, results in slow dynamics and sluggish response. Moreover, operations of Volts/Hertz are characterized by large transient behaviors in the motor currents and torque [28].

\section{B. Particular Case of the Sensorless Vector Control}

Induction motor drive research has been concentrated on the elimination of speed sensors at the motor shaft without deteriorating the dynamic performance of the drive-control system. The advantages of speed sensorless ac drives are lower cost, reduced size of the motor set, cable elimination, and increased reliability. Different schemes for speed sensorless in the field orientation have been proposed in the past few years. A comprehensive review of the sensorless control of ac drives is given in [29], in which their merits and limits based on a survey of the available literature are reviewed.

According to the survey above, we present a practical solution to estimate the induction motor speed in the rotor-flux-oriented control-system frame, taking into account rotor-resistance variations. In fact, the vector-control strategy is very sensitive to flux estimation, which is mainly altered by motor parameter variations. It was then imperative to identify them [30], [31]. Moreover, fast flux estimation and parameter identification achieves high dynamic performance and speed accuracy. Such features have been considered in the proposed control scheme [32], [33].

1) Induction Motor Model: An induction motor model can be described in a stator reference frame with

$$
\left[\begin{array}{c}
\frac{d \bar{i}_{s}}{d t} \\
\frac{d \bar{\varphi}_{r}}{d t}
\end{array}\right]=\left[\begin{array}{cc}
\gamma & \frac{K}{T_{r}}-j \omega K \\
\frac{M}{T_{r}} & -\frac{1}{T_{r}}+j \omega
\end{array}\right]\left[\begin{array}{c}
\bar{i}_{s} \\
\bar{\varphi}_{r}
\end{array}\right]+\left[\begin{array}{l}
1 \\
0
\end{array}\right] \frac{\bar{V}_{s}}{\sigma L_{s}} .
$$

The rotor flux orientation is achieved by the following transformation from the $\alpha-\beta$ to $d-q$ frame:

$$
\left[\begin{array}{l}
x_{d} \\
x_{q}
\end{array}\right]=\frac{1}{\sqrt{\varphi_{r \alpha}^{2}+\varphi_{r \beta}^{2}}}\left[\begin{array}{cc}
\varphi_{r \alpha} & \varphi_{r \beta} \\
-\varphi_{r \beta} & \varphi_{r \alpha}
\end{array}\right]\left[\begin{array}{l}
x_{\alpha} \\
x_{\beta}
\end{array}\right]
$$

This transformation leads to

$$
\left\{\begin{array}{l}
\varphi_{r d}=\sqrt{\varphi_{r \alpha}^{2}+\varphi_{r \beta}^{2}} \\
\varphi_{r q}=0
\end{array}\right.
$$

Fig. 1 shows the general structure in which flux and torque, respectively, are controlled by currents $i_{s d}$ and $i_{s q}$ in the synchronous rotating frame fixed with the flux.

2) Speed Estimator: If we choose the motor speed $\omega$ as an intermediate variable, (1) could be written as

$$
\left\{\begin{array}{l}
\frac{d \bar{i}_{s}}{d \omega} \frac{d \omega}{d t}=\gamma \bar{i}_{s}+\left(\frac{1}{T_{r}}-j \omega\right) K \bar{\varphi}_{r}+\frac{\bar{V}_{s}}{\sigma L_{s}} \\
\frac{d \bar{\varphi}_{r}}{d \omega} \frac{d \omega}{d t}=\frac{M}{T_{r}} \bar{i}_{s}-\left(\frac{1}{T_{r}}-j \omega\right) \bar{\varphi}_{r}
\end{array}\right.
$$

From the above, the following is then obtained:

$$
\begin{aligned}
\left(\frac{d \bar{\varphi}_{r}}{d \bar{i}_{s}}\right)\left(\gamma \bar{i}_{s}+\left(\frac{1}{T_{r}}-j \omega\right)\right. & \left.K \bar{\varphi}_{r}+\frac{\bar{V}_{s}}{\sigma L_{s}}\right) \\
= & \frac{M_{T_{r}}}{T_{s}}-\left(\frac{1}{T_{r}}-j \omega\right) \bar{\varphi}_{r}
\end{aligned}
$$




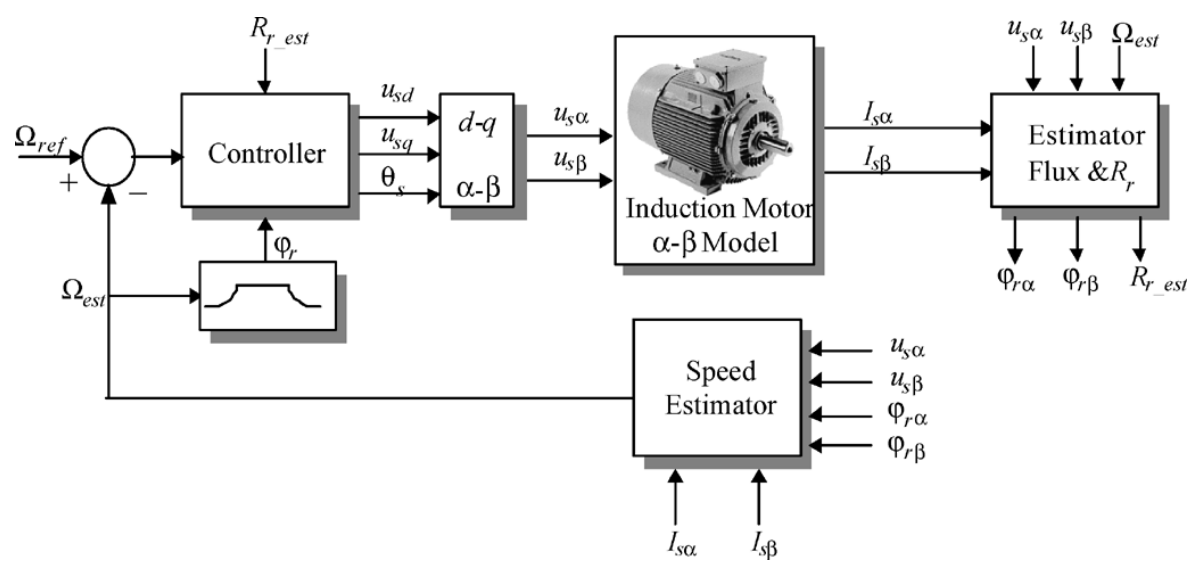

Fig. 1. Induction motor control structure.

where $d \bar{\varphi}_{r} / d \bar{i}_{s}$ represents the slope value for each point of the induction motor magnetic characteristic

$$
\bar{\varphi}_{r}=L_{r} \bar{i}_{r}+M \bar{i}_{s} .
$$

The magnetic saturation is neglected on the basis of a physical consideration. In fact, the induction motor temperature increases (thermal effect) due to its operation and will perturb and slow down the magnetic saturation process [32]. Moreover, induction motors designed for $\mathrm{EV}$ applications are required to have a small total leakage inductance in order to maximize the peak torque and constant KVA region. Therefore, open-slot shallow-bar rotors are typically used. This results in no saturation of the leakage inductance. Traction motors also are typically designed for high efficiency. Therefore, the specific losses (power/unit mass) of the core are minimized. This is accomplished by using core materials with a lower relative permeability, resulting in a higher saturation flux density. Therefore, the overall saturation of the main flux is reduced and the main inductance is nearly constant over the operating range [34]. The EV drive system, which requires knowledge of the motor parameters, is susceptible to detuning primarily because of the motor resistances and not because of the inductances.

These practical considerations have led us to consider $M$ as a constant. In this case

$$
\frac{d \bar{\varphi}_{r}}{d \bar{i}_{s}}=L_{r} \frac{d \bar{i}_{r}}{d \bar{i}_{s}}+M
$$

This equation can be written as

$$
\frac{d \bar{\varphi}_{r}}{d \bar{i}_{s}}=K_{\mathrm{sat}}
$$

where $K_{\text {sat }}$ represents the magnetic characteristic slope that changes with the motor load. In fact, the first part of (7) may be written as

$$
L_{r} \frac{d \bar{i}_{r}}{d \bar{i}_{s}}=L_{r}\left(\frac{d \bar{i}_{s}}{d t}\right)^{-2}\left(\frac{d \bar{i}_{r}}{d t} \bullet \frac{d \bar{i}_{s}}{d t}+j\left(\frac{d \bar{i}_{r}}{d t} \times \frac{d \bar{i}_{s}}{d t}\right)\right) .
$$

In this case, it is numerically checked that the real part absolute value of (9) increases and does not exceed the mutual inductance value in loaded conditions. Furthermore, we have noticed that the imaginary part remains slight. Therefore, the following two

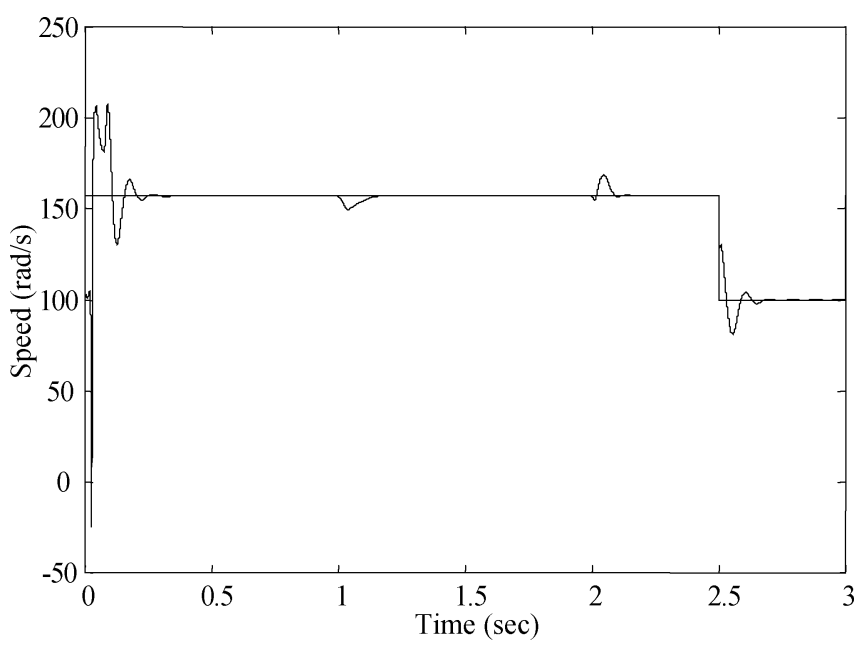

Fig. 2. Speed estimation with a $200 \%$ increase of $R_{r}$.

statements are derived: $K_{\text {sat }}=M$ for unloaded motor operation

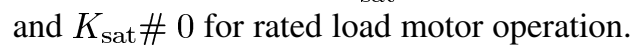

With the above considerations and, in the particular case of small and medium power induction motors, the following approximation could be written:

$$
K_{\mathrm{sat}} \approx M .
$$

From (10) and (5), the motor speed estimator is extracted.

$\hat{\omega}=\frac{1}{\left(K+\frac{1}{M}\right)} \frac{1}{\hat{\varphi}_{r}^{2}}\left[\left(\gamma-\frac{1}{T_{r}}\right)\left(\bar{i}_{s} \times \hat{\varphi}_{r}\right)+\frac{1}{\sigma L_{s}}\left(\bar{V}_{s} \times \hat{\varphi}_{r}\right)\right]$.

As shown by (11), the speed estimator is composed of two terms. The first has the drawback of being sensitive to rotor and stator resistance that may vary owing to temperature. However, at the motor-rated load operation, we have

$$
\frac{1}{\left(K+\frac{1}{M}\right)} \frac{1}{\varphi_{r}^{2}} \ll 1
$$

Therefore, the parameter variation influence is reduced.

3) Simulation Results: Numerical simulations have been carried out on a 4-kW induction motor, whose ratings are summarized in Table 1, to analyze the proposed speed sensorless induction motor drive (Fig. 1) performance. 


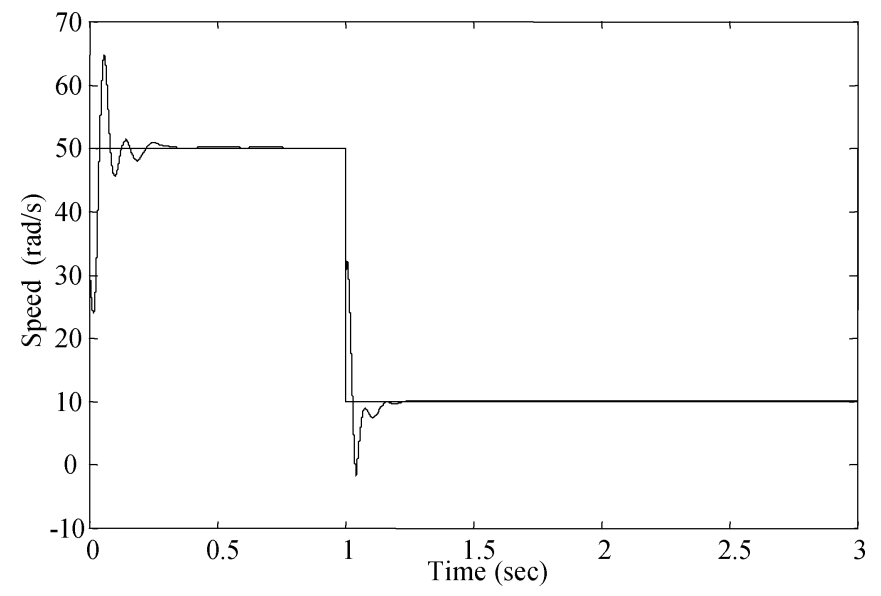

Fig. 3. Low-speed estimation with $20 \mathrm{Nm}$ of load torque.

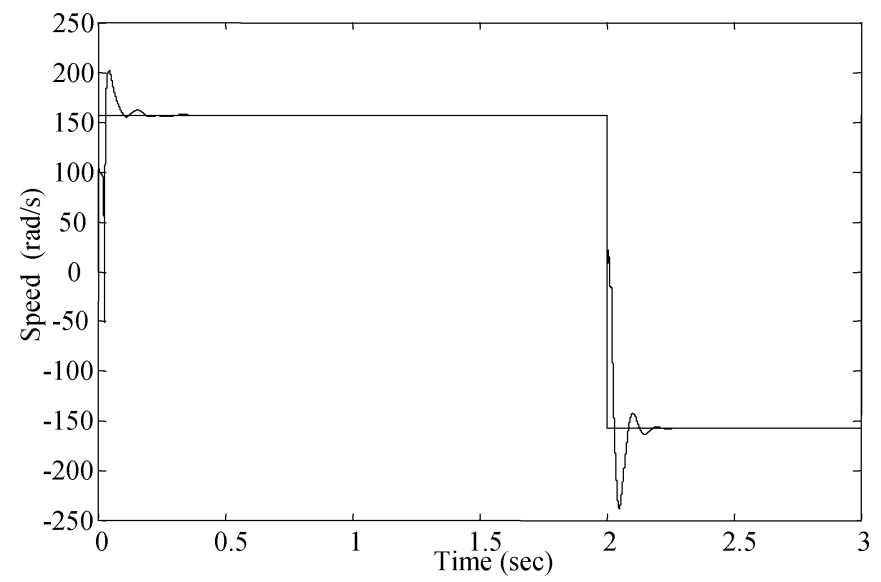

Fig. 4. Speed estimation with $20 \mathrm{Nm}$ of load torque.

For simulation purposes, the transient behavior of the speed estimator is evaluated during $3 \mathrm{~s}$. At $1 \mathrm{~s}$, a $15-\mathrm{Nm}$ load torque is applied and removed at $2 \mathrm{~s}$. In these conditions, Fig. 2 shows that good performances are achieved and demonstrates the speedestimator robustness against parameter variations. Moreover, a change in the speed reference at $2.5 \mathrm{~s}$ is well tracked. Figs. 3 and 4 demonstrate the speed-estimator capability for different induction motor-operation conditions, particularly those at low speed.

To illustrate the speed-estimator robustness, computer simulations have been carried out in the case of an induction motor fed by a PWM-VSI inverter. Fig. 5 clearly shows the robustness of the proposed speed estimator when a $15-\mathrm{Nm}$ load torque is applied at $1 \mathrm{~s}$ and removed at $2 \mathrm{~s}$ and when the speed reference is changed at $2.5 \mathrm{~s}$.

\section{FAULT-TOLERANT CONTROL}

The high-impact nature of many electric machine applications, such as starter/alternator systems in automobiles (Fig. 6), necessitates a fault-tolerant performance. This can be realized in a flexible controller architecture that maintains maximum performance in the event of a failure in any part of the EV or HEV electric drive.

To achieve this goal, a reorganizing controller will adopt the best control methodology according to the available feedback

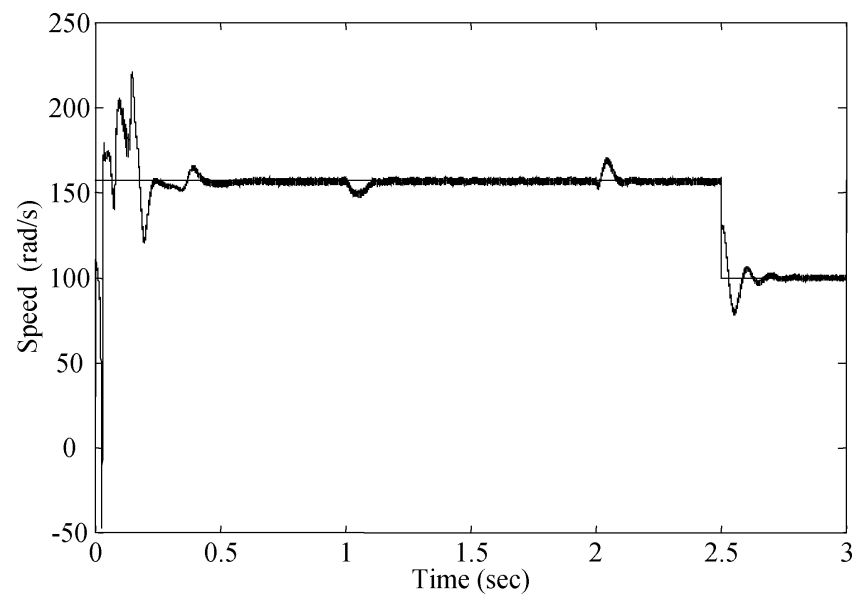

Fig. 5. Speed estimation when a PWM-VSI inverter feeds the motor.

and the operational hardware. Therefore, the reorganizing controller (fault-tolerant controller, as illustrated by Fig. 7 in the case of a parallel HEV) comprises two parts: failure detection and fallback strategy. While the first part monitors the status of system components such as sensors, motor, inverter, etc., the latter will engage the most appropriate control strategy based on a hierarchical basis as presented in Section II.

\section{A. Induction Motor Drive Control in Presence of Faults}

Vector-controlled ac drives have been proven to be capable of even better dynamic performance than direct current (dc) drive systems. However, direct field-orientation schemes would require the use of flux sensors (search coils) installed inside the motor. These would spoil the ruggedness of the motor and are useless at low speeds. Indirect field orientation is based on sensing the rotor position that is very sensitive to motor parameters. Incorrect knowledge of these leads to significant deterioration of the drive performance. In the case of sensor failure, they are replaced by observers, which convert the stator voltage and current signals into the required information concerning flux or motor speed. However, observer performances are mainly affected by rotor time-constant variation due to temperature and saturation. This will substantially deteriorate the induction motor drive performance.

Another control technique is then needed, even for lower performance. The closed-loop scalar control is suitable in this case. Finally, if current sensors break down, the Volts/Hertz control technique is then substituted to guarantee drive-system continuity.

\section{B. Fault-Tolerant Controller}

A fault-tolerant control system with automatic controller reconfiguration has been developed. Depending on the functionality of the sensors, the appropriate control strategy will be used. The fault-tolerant control system first concerns the indirect vector-control (IVC) technique, since better performance is obtained with an encoder to get the speed information. In the event of unavailability of the speed sensor (e.g., failures in measurements or in the device), a sensorless vector-control (SVC) technique is applied. However, in high-speed ranges, angular delay between the control and motor frames becomes 


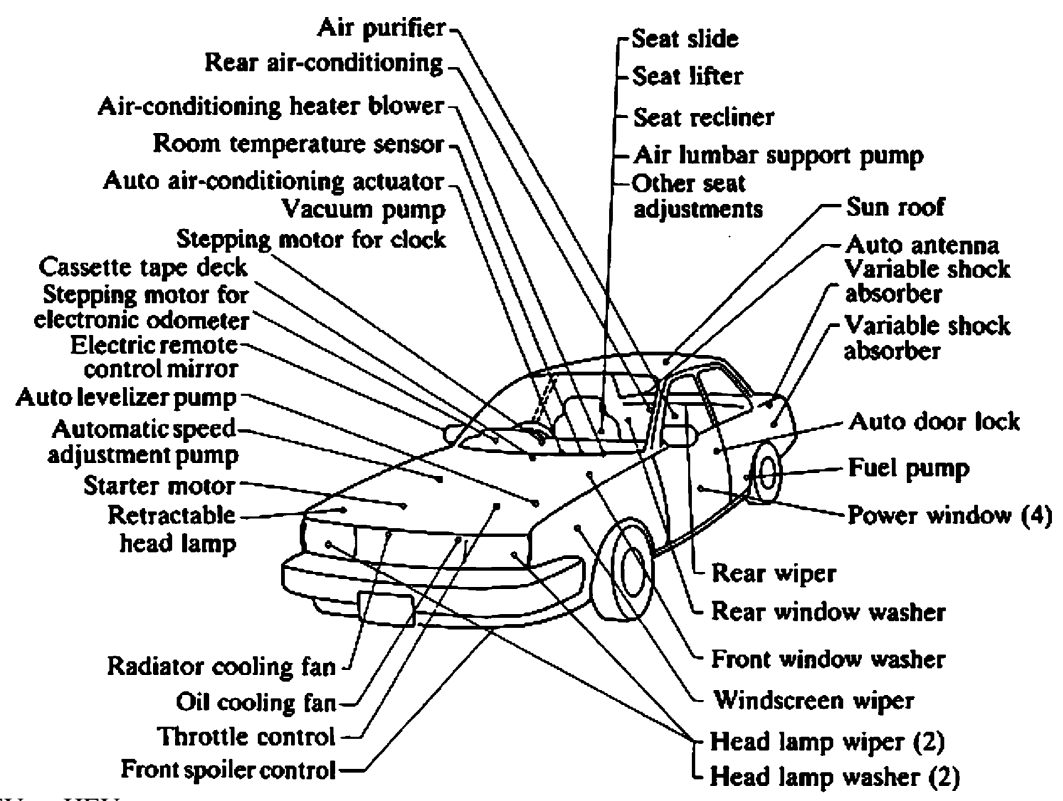

Fig. 6. Electric motors in an EV or HEV.

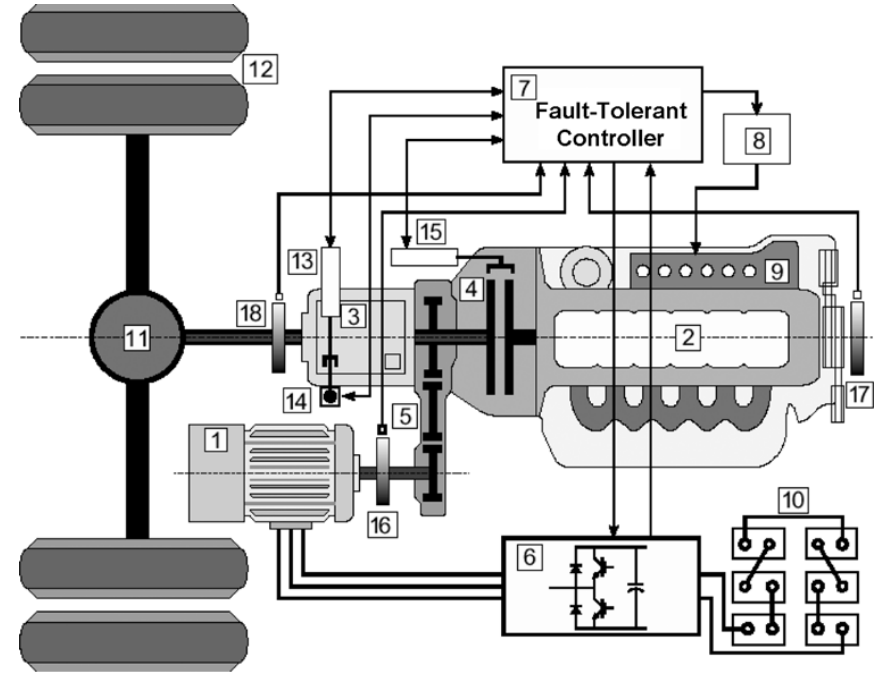

1. Induction motor, 2. Diesel engine, 3. Transmission, 4. Clutch, 5. Inlet gearing, 6. Inverter, 7. Fault-tolerant controller, 8. Throttle actuator, 9. Electronic fuel injector, 10. Battery, 11. Differential gear, 12. Wheels,

13. Horizontal pneumatic actuator, 14. Vertical pneumatic actuator,

15. Clutch pneumatic actuator, 16, 17, and 18. Saw-tooth wheel.

Fig. 7. Schematic block diagram of a hybrid drivetrain.

so important that instability may occur. Therefore, even if dynamic performance is reduced, we have to use the closed-loop sensorless scalar control (SSC), which guarantees stability. Finally, if the current sensors are unfortunately ineffective, an open-loop $V / f$ law will be used to avoid the complete stalling of the EV or HEV engine.

Fig. 8 shows the proposed flexible architecture for fault-tolerant control purposes that maintains maximum performance, as well as the overall system failure rate at an acceptable level. With this approach, the reliability of the drive system is greatly improved.

\section{Controller Transition Strategy}

The control-transition smoothness depends greatly on the rotor flux angular position in the stator reference frame. In fact, the flux angle generator runs in parallel and integrates the motor voltage to determine the machine flux. This calculated machine flux is not used by the IVC controller, but is available in the event of a switchover to the SVC controller being required, depending on the control technique type

$$
\theta_{s}=\int \omega_{s} d t
$$

The calculated angles for vector (SVC) or scalar (SSC) control techniques reveal a slight difference, as can be seen in Fig. 9. However, if a transition strategy is not used, an important braking torque with probable mechanical damage will occur, as Fig. 10 shows. Indeed, this braking torque is a direct consequence of the phase shift between control voltages $V$, as illustrated by Fig. 11 .

Therefore, to obtain a smooth transition, this should be done when phase-shift $\Delta \theta$ is zero or very close to zero (Fig. 12). In [14], the transition technique is to force synchronization between the encoder-based angle generator and the SVC angle generator by compensating for their phase difference at the instant of controller switchover. In our case, after a sensor fault, the controller switchover is authorized when synchronization has been naturally achieved $(\Delta \theta=0)$.

\section{Simulation Results}

\section{A. Tests of the Fault-Tolerant Controller}

The proposed fault-tolerant control strategy has been simulated on a 4-kW squirrel cage induction motor whose ratings are summarized in Table I.

In Figs. 13 and 14, a set of speed and torque curves shows smooth controller transitions $(\Delta \theta=0)$ and abrupt ones $(\Delta \theta \neq$ $0)$. The following event sequences have been implemented.

Step 1) At $0.5 \mathrm{~s}$, a disturbance in the form of missing the speed sensor pulses was introduced (speed sensor failure). 


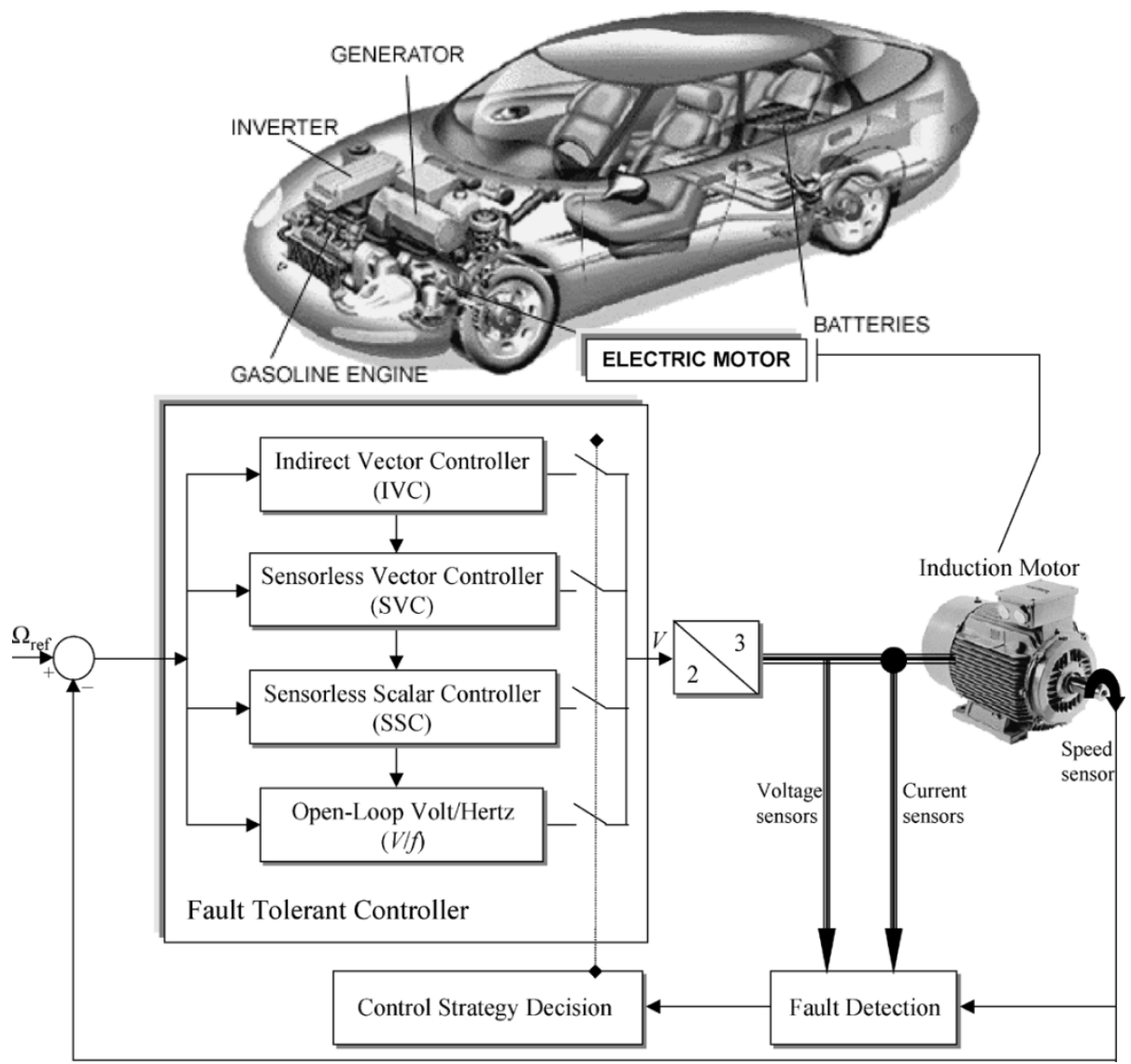

Fig. 8. Overall system structure.

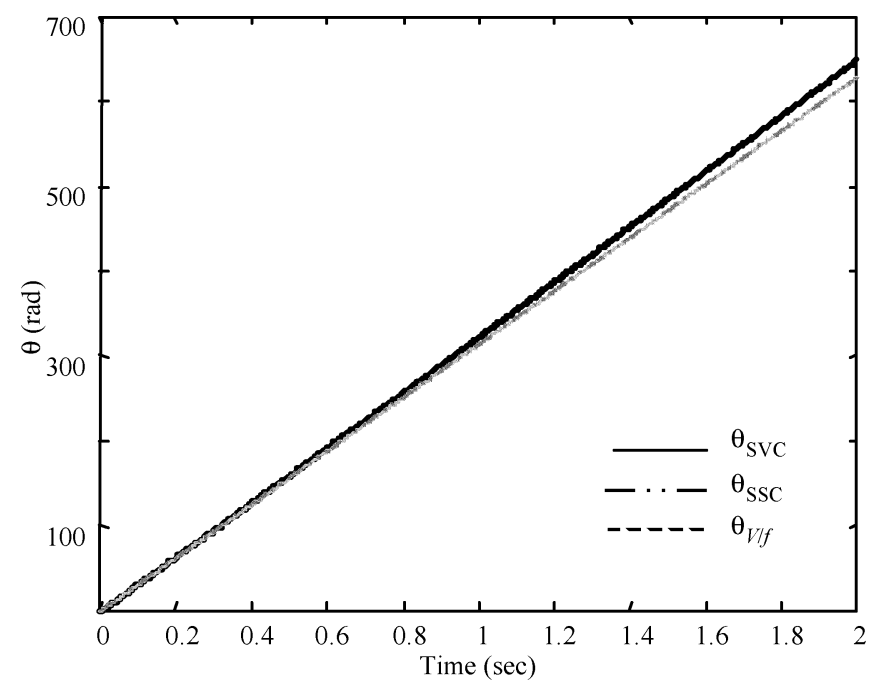

Fig. 9. Rotor flux angle for different control methods.

Step 2) At $1.2 \mathrm{~s}$, the rotor flux orientation cannot be maintained (e.g., loss of access to the rotor flux angle). Therefore, there is need for a scalar control method to guarantee the stability. As expected and shown in Fig. 13, dynamic performances are deteriorated.

Step 3) At $1.8 \mathrm{sec}$, current sensors are failed. The Volts/Hertz control technique is then engaged.
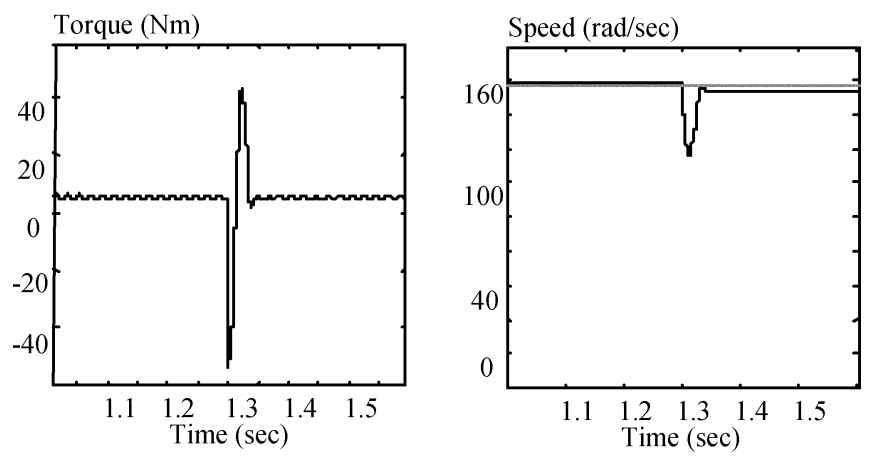

Fig. 10. Torque and speed responses with a transition from vector to scalar control of the induction motor drive.

This is the last step in the hierarchical classification of the control strategies for the induction motor drive.

Although voltage sensors are typically not used, the application of a desired voltage to the induction motor without the need for voltage sensors implies that the inverter bus voltage is known.

In most cases, we observe an oscillatory behavior when the speed sensor fails. The torque oscillations for $\Delta \theta=0$ have a small amplitude with a quite null average and are quickly damped. On the contrary, when $\Delta \theta \neq 0$, the average torque is negative, leading to a braking torque, which is confirmed by the speed deceleration illustrated by Fig. 14. 


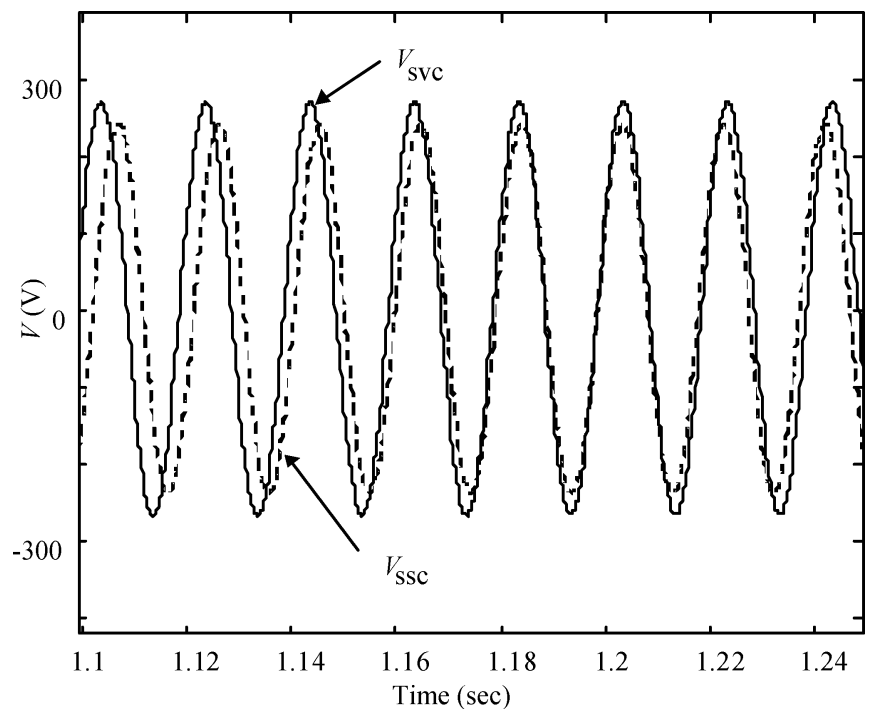

Fig. 11. Control voltages for vector and scalar control of the induction motor drive.

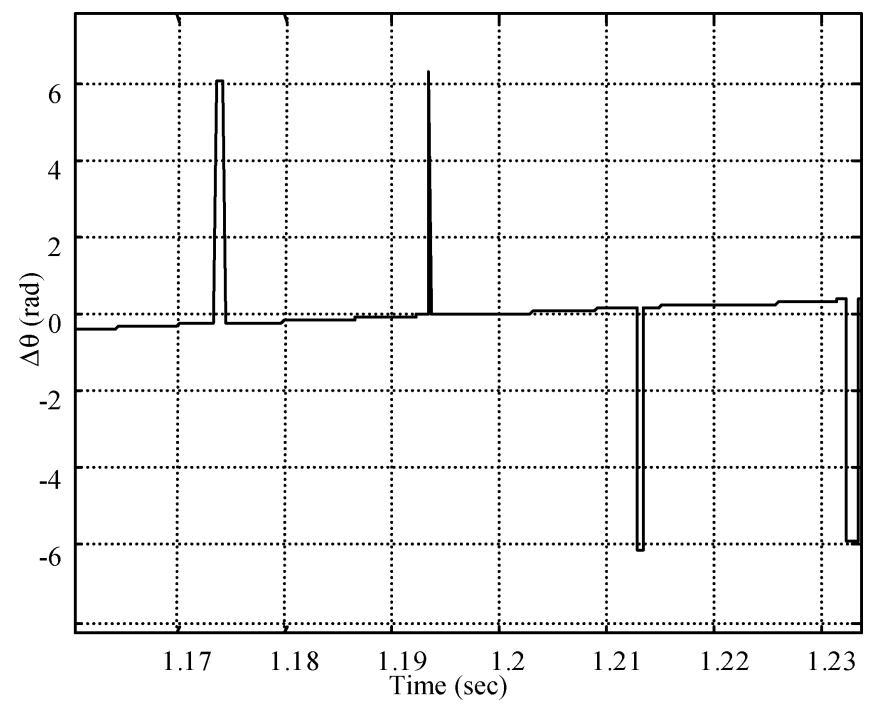

Fig. 12. Rotor flux angular phase shift for vector and scalar control of the induction motor drive.

TABLE I

RATED DATA OF THE SimUlATED INDUCTION MOTOR

\begin{tabular}{llll}
\hline Rated Values & Power & 4 & $\mathrm{KW}$ \\
& Frequency & 50 & $\mathrm{~Hz}$ \\
& Voltage $(\Delta / \mathrm{Y})$ & $220 / 380$ & $\mathrm{~V}$ \\
& Current $(\Delta / \mathrm{Y})$ & $15 / 8.6$ & $\mathrm{~A}$ \\
& Speed & 1440 & $\mathrm{rpm}$ \\
& Pole pair $(\mathrm{p})$ & 2 & \\
Rated parameters & $R_{S}$ & 1.2000 & $\Omega$ \\
& $R_{r}$ & 1.8000 & $\Omega$ \\
& $L_{S}$ & 0.1554 & $\mathrm{H}$ \\
& $L_{r}$ & 0.1566 & $\mathrm{H}$ \\
& $M$ & 0.1500 & $\mathrm{H}$ \\
& $J$ & 0.013 & $\mathrm{Kg} . \mathrm{m}^{2}$ \\
\hline
\end{tabular}

\section{B. EV or HEV Cases}

It should be noted that there are many hybrid schemes, which combine attributes of the control methods discussed previously. Depending on the application and availability of

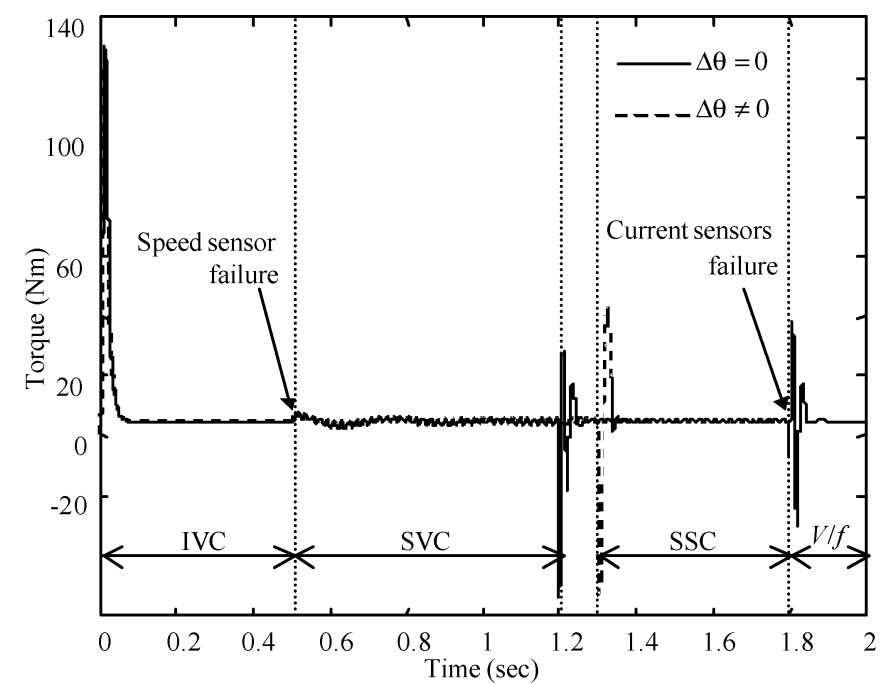

Fig. 13. Torque response according to controller transitions.

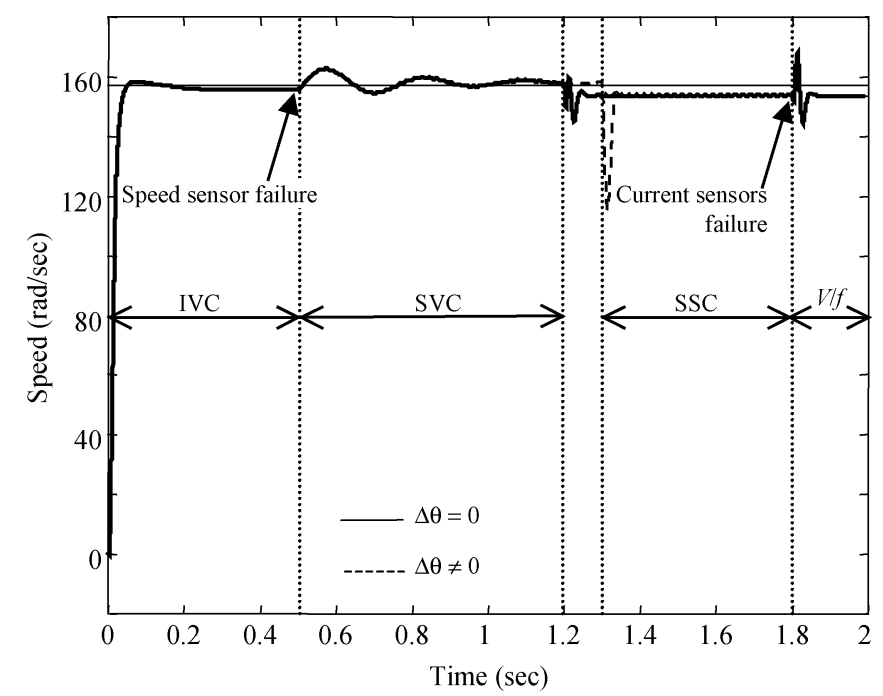

Fig. 14. Speed response according to controller transitions.

sensors, as well as the desired performance of the system, other controller permutations may be possible to add to the hierarchy described here [24], [35]. Conventional linear control such as PID can no longer satisfy the stringent requirements placed on high-performance EV or HEV. In recent years, many modern control strategies, such as model-referencing adaptive control (MRAC), self-tuning control (STC), variable structure control (VSC), fuzzy control (FC), and neural network control (NNC), have been proposed [36]. Both MRAC and STC have been successfully applied to EV propulsion [37]. Using the sliding mode, VSC has also been applied to motor drives [38]. By employing the emerging technologies of fuzzy and neural networks to realize the concept of intelligent controllers, FC and NNC offer promising applications to EV and HEV propulsion [39]-[43].

Automotive application drives such as EV require an ability to operate at constant power over a wide speed range, good overload performance, and high efficiency, especially at light load operation at higher speeds (Fig. 15). These characteristics allow the best utilization of the limited battery capacity (extension of 


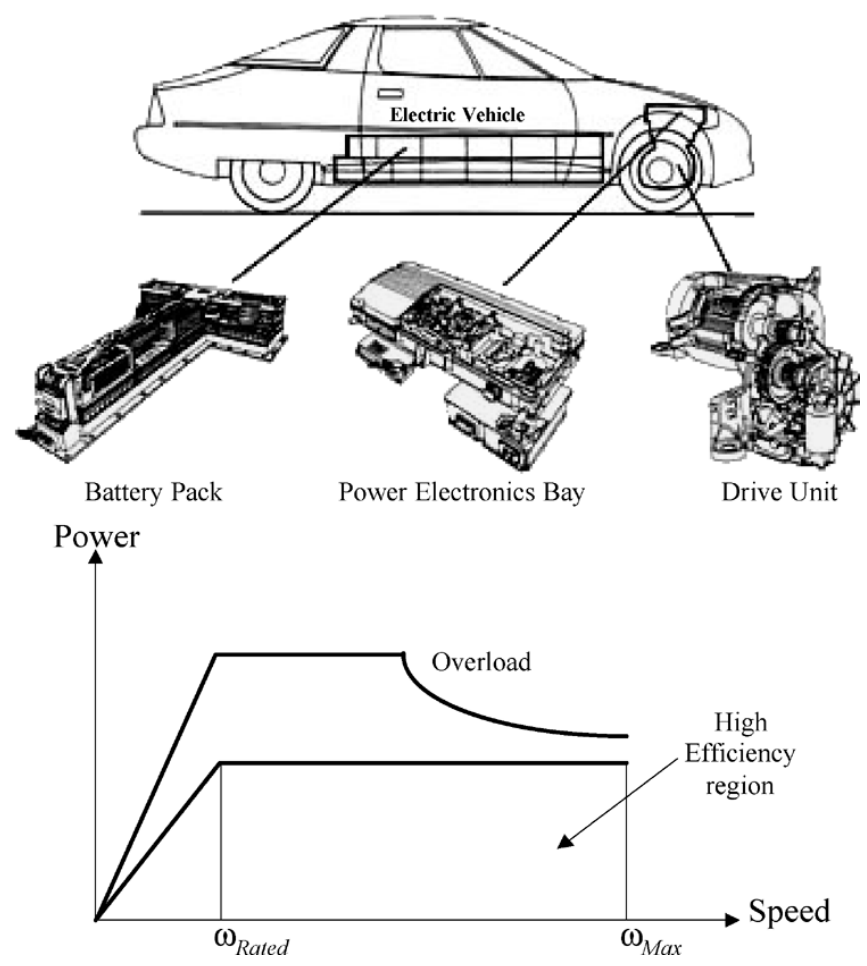

Fig. 15. EV drive system requirements.

the running distance per battery charge) and the minimization of the size and weight of the motor and drive. For these requirements, induction motor vector-control advantages (quick and precise torque) are not sufficient. Therefore, control techniques that maximize the induction motor efficiency are highly desirable for the fault-tolerant controller [23], [44]-[50].

\section{CONCLUDING REMARKS}

This paper has described a fault-tolerant control system for a high-performance induction motor drive for automotive applications. The proposed system adaptively changes control techniques in the event of sensor failures. Four control techniques have been used to ensure induction motor drive operation continuity. Among these, a practical sensorless control technique has been developed, which requires the presence of an adaptive flux observer. The speed estimator is based on the approximation of the magnetic characteristic slope of the induction motor to the mutual inductance value, which is considered to be constant.

This assumption is based on the fact that the sensorless technique is dedicated to EV or HEV applications. In fact, in induction motors designed for automotive applications, the main inductance is nearly constant over the operating range [34]. Computer simulations on a 4-kW induction motor drive show the feasibility and robustness of the proposed speed estimator. Furthermore, a management technique has been introduced to guarantee a smooth transition between two control techniques in the case of sensor failures.

The transition technique is to authorize controller switchover when the control voltages are naturally synchronized $(\Delta \theta=0)$. Simulations results on the same $4-\mathrm{kW}$ induction motor drive, in terms of speed and torque responses, show the effectiveness of the proposed approach. Finally, there are many hybrid schemes that combine attributes of the above tested control methods. Moreover, depending on the application and availability of sensors and the desired performance of the system, it may be possible to add other controller permutations to the hierarchy described here.

\section{ACKNOWLEDGMENT}

The authors would like to thank L. Guyot from Institut Universitaire Professionnalisé-Génie Electrique et Informatique Industrielle (IUP GEII) Amiens for the text review.

\section{REFERENCES}

[1] D. Kastha and B. K. Bose, "Investigation of fault modes of voltage-fed inverter system for induction motor drive," IEEE Trans. Ind. Applicat., vol. 30, pp. 426-433, July 1994.

[2] K. S. Smith, L. Ran, and J. Penman, "Real-time detection of intermittent misfiring in a voltage-fed PWM inverter induction-motor drive," IEEE Trans. Ind. Electron., vol. 44, pp. 468-476, Aug. 1997.

[3] M. E. H. Benbouzid, "Bibliography on induction motors faults detection and diagnosis," IEEE Trans. Energy Conversion, vol. 14, pp. 1065-1074, Dec. 1999.

[4] _ - "A review of induction motors signature analysis as a medium for faults detection," IEEE Trans. Indu. Electron., vol. 47, pp. 984-993, Oct. 2000.

[5] R. Spée and A. K. Wallace, "Remedial strategies for brushless DC drive failures," IEEE Trans. Ind. Applicat., vol. 26, no. 2, pp. 259-266, Mar. 1990.

[6] C. M. Stephens, "Fault detection and management system for fault-tolerant switched reluctance motor drives," IEEE Trans. Ind. Applicat., vol. 27, pp. 1098-1102, Nov. 1991.

[7] T. H. Liu, J. R. Fu, and T. A. Lipo, "A strategy for improving reliability of field-oriented controlled induction motor drives," IEEE Trans. Ind. Applicat., vol. 29, pp. 910-918, Sept. 1993.

[8] D. Kastha and B. K. Bose, "Fault mode single-phase operation of a variable frequency induction motor drive and improvement of pulsating torque characteristics," IEEE Trans. Ind. Electron., vol. 41, pp. 426-432, Aug. 1994.

[9] S. Bolognani, M. Zordan, and M. Zigliotto, "Experimental fault-tolerant control of PMSM drive," IEEE Trans. Ind. Electron., vol. 47, pp. 1134-1141, Oct.r 2000.

[10] M. B. de Rossier Corrêa, C. B. Jacobina, E. R. C. da Silva, and A. N. Lima, "An induction motor drive system with improved fault tolerance," IEEE Trans. Ind. Applicat., vol. 37, pp. 873-879, May 2001.

[11] J. A. Haylock, B. C. Mecrow, A. G. Jack, and D. J. Atkinson, "Operation of fault tolerant machines with winding failures," IEEE Trans. Energy Conversion, vol. 14, pp. 1490-1495, Dec. 1999.

[12] K. M. Rahman, B. Fahmi, G. Suresh, A. V. Rajarathnam, and M. Ehsani, "Advantages of switched reluctance motor applications to EV and HEV: Design and control issues," IEEE Trans. Ind. Applicat., vol. 36, pp. 111-121, Jan. 2000.

[13] A. G. Jack, B. C. Mecrow, and J. A. Haylock, "A comparative study of permanent magnet and switched reluctance motors for high-performance fault tolerant applications," IEEE Trans. Ind. Applicat., vol. 32, pp. 889-895, July 1996

[14] R. B. Sepe, B. Fahmi, C. Morrison, and J. M. Miller, "Fault tolerant operation of induction motor drives with automatic controller reconfiguration," in IEEE Int. Electric Machines and Drives Conf. (IEMDC'01), Cambridge, MA.

[15] S. Naito, N. Mutoh, T. Takagi, and Y. Kouchi, "AC drive system for electric vehicles," Hitachi Hyoron, vol. 77, no. 2, pp. 33-38, 1995.

[16] C. C. Chan and K. T. Chau, "An overview of power electronics in electric vehicles," IEEE Trans. Ind. Electron., vol. 44, pp. 3-13, Feb. 1997.

[17] J. M. Miller, A. R. Gale, P. J. McCleer, and J. H. Lang, "Starter-alternator for hybrid electric vehicle: comparison of induction and variable reluctance machines and drives," in Proc. IEEE Industry Applications Society (IAS) Annu. Meeting, St. Louis, MO, 1998, pp. 513-523.

[18] W. Leonhard, Control of Electrical Drives. Berlin, Germany: Springer-Verlag, 1985.

[19] G. Heinemann, "Comparison of several control schemes for ac induction motors," in Proc. Eur. Power Electronics Conf. (EPE'89), Aachen, Germany, 1989, pp. 843-844. 
[20] K. Rajashekara, "History of electric vehicles in general motors," IEEE Trans. Ind. Applicat., vol. 30, pp. 897-904, July 1994.

[21] N. Mutoh, S. Kaneko, T. Miyazaki, R. Masaki, and S. Obara, "A torque controller suitable for electric vehicles," IEEE Trans. Ind. Electron., vol. 44, pp. 54-63, Feb. 1997.

[22] J. Jung and K. Nam, "A vector control schemes for ev induction motors with a series iron loss model," IEEE Trans. Ind. Electron., vol. 45, pp. 617-624, Aug. 1998.

[23] C. M. Ta and Y. Hori, "Convergence improvement of efficiency-optimization control of induction motor drives," IEEE Trans. Ind. Applicat., vol. 37, pp. 1746-1754, Nov. 2001

[24] D. O. Neacsu and K. Rajashekara, "Comparative analysis of torque-controlled IM drives with applications in electric and hybrid vehicles vehicle," IEEE Trans. Power Electron., vol. 16, pp. 240-247, Mar. 2001.

[25] G. O. Garcia, R. M. Stephan, and E. H. Watanabe, "Comparing the indirect field-oriented control with a scalar method," IEEE Trans. Ind. Electron., vol. 41, pp. 201-207, Apr. 1994.

[26] P. L. Jansen, R. D. Lorenz, and D. W. Novotny, "Observer-based direct field orientation: Analysis and comparison of alternative methods," IEEE Trans. Ind. Applicat., vol. 30, pp. 945-953, July 1994.

[27] B. K. Bose, "Scalar decoupled control of induction motor," IEEE Trans. Ind. Applicat., vol. IA-20, pp. 216-225, Jan. 1984

[28] T. A. Lipo, "Recent progress in the development of solid state ac motor drives," IEEE Trans. Power Electron., vol. PEL-3, pp. 105-117, Apr. 1988.

[29] J. Holtz, "Methods for speed sensorless control of AC drives," in Sensorless Control of AC Motor Drives. Piscataway, NJ: IEEE Press, 1996

[30] J. Maes and J. A. Melkebeek, "Speed-sensorless direct torque control of induction motors using an adaptive flux observer," IEEE. Trans. Ind. Applicat., vol. 36, pp. 778-785, May 2000

[31] K. Akatsu and A. Kawamura, "Online rotor resistance estimation using the transient state under the speed sensorless control of induction motor," IEEE Trans. Power Electron., vol. 15, pp. 553-560, May 2000.

[32] M. E. H. Benbouzid and M. S. Naït-Saïd, "Induction motors direct field oriented control with robust on-line tuning of rotor resistance," IEEE Trans. Energy Conversion, vol. 14, pp. 1038-1042, Dec. 1999.

[33] T. Noguchi, S. Kondo, and S. Takahashi, "Field-orientated control of an induction motor with robust on-line tuning of its parameters," IEEE Trans. Ind. Applicat., vol. 33, pp. 35-42, Jan. 1997.

[34] T. G. Habetler, F. Profumo, G. Griva, M. Pastorelli, and A. Bettini, "Stator resistance tuning in a stator-flux field-oriented drive using an instantaneous hybrid flux estimator," IEEE Trans. Power Electron., vol. 13, pp. 125-133, Jan. 1998

[35] J. Faiz and M. B. B. Sharifian, "Different techniques for real time estimation of an induction motor rotor resistance in sensorless direct torque control for electric vehicle," IEEE Trans. Energy Conversion, vol. 16, pp. 104-109, Mar. 2001

[36] C. C. Chan, "The state of the art of electric and hybrid vehicles," Proc. IEEE, vol. 90, pp. 247-275, Feb. 2002

[37] C. C. Chan, W. S. Leung, and C. W. Ng, "Adaptive decoupling control of induction motor drives," IEEE Trans. Ind. Electron., vol. 37, pp. 41-47, Feb. 1990.

[38] V. I. Utkin, "Sliding mode control design principles and applications to electric drives," IEEE Trans. Ind. Electron., vol. 40, pp. 23-36, Feb. 1993.

[39] B. Asaii, D. F. Gosden, and S. Sathiakumar, "A new technique for highly efficient sensor-less control of electric vehicles by using neural networks," in Proc. IEEE Power Electronics in Transportation Conf., Dearborn, MI, 1996, pp. 143-149.

[40] B. K. Bose, N. R. Patel, and K. Rajashekara, "A neuro-fuzzy-based on-line efficiency optimization control of a stator flux-oriented direct vector-controlled induction motor drive," IEEE Trans. Ind. Electron., vol. 44, pp. 270-273, Apr. 1997.

[41] H. D. Lee and S. K. Sul, "Fuzzy-logic-based torque control strategy for parallel-type hybrid electric vehicle," IEEE Trans. Ind. Electron., vol. 45, pp. 625-632, Aug. 1998.

[42] H. Huang and L. Chang, "Electrical two-speed propulsion by motor winding switching and its control strategies for electric vehicles," IEEE Trans. Veh. Technol., vol. 48, pp. 607-618, Mar. 1999.

[43] H. Gao, Y. Gao, and M. Ehsani, "A neural network based srm drive control strategy for regenerative braking in EV and HEV," presented at the IEEE Int. Electric Machines and Drives Conf. (IEMDC'01), Cambridge, MA, 2001.

[44] G. O. Garcia et al., "An efficient controller for an adjustable speed induction motor drive," IEEE Trans. Ind. Electron., vol. 41, pp. 533-539, Oct. 1994.
[45] G. C. D. Sousa, B. K. Bose, and J. G. Cleland, "Fuzzy logic based on-line efficiency optimization control of an indirect vector-controlled induction motor drive," IEEE Trans. Ind. Electron., vol. 42, pp. 192-198, Apr. 1995.

[46] I. Kioskeridis and N. Margaris, "Loss minimization in scalar-controlled induction motor drives with search controllers," IEEE Trans. Power Electron., vol. 11, pp. 213-220, Mar. 1996.

[47] B. K. Bose, N. R. Patel, and K. Rajashekara, "A neuro-fuzzy-based on-line efficiency optimization control of a stator flux-oriented direct vector-controlled induction motor drive," IEEE Trans. Ind. Electron., vol. 44, pp. 270-273, Apr. 1997.

[48] M. E. H. Benbouzid and M. S. Naït Saïd, "An efficiency-optimization controller for induction motor drives," IEEE Power Eng. Lett., vol. 18 , pp. 43-45, May 1998

[49] F. Zidani, M. E. H. Benbouzid, and D. Diallo, "Fuzzy efficient-optimization controller for induction motor drives," IEEE Power Eng. Lett., vol. 20, pp. 43-44, Oct. 2000.

[50] F. Zidani, M. S. Naït-Saïd, D. Diallo, and M. E. H. Benbouzid, "Fuzzy optimal Volts/Hertz control method for an induction motor," presented at the IEEE Int. Electric Machines and Drives Conf. (IEMDC'01), Cambridge, MA.

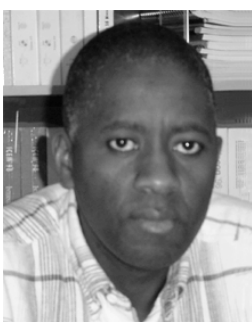

Demba Diallo (M'99) was born in Dakar, Senegal, in 1966. He received the M.Sc. and Ph.D. degrees in electrical and computer engineering from the $\mathrm{Na}$ tional Polytechnic Institute of Grenoble, Grenoble, France, in 1990 and 1993, respectively.

From 1994 to 1999, he was a Research Engineer in the Laboratoire d'Electrotechnique, Grenoble, where he worked on electrical drives and active filters (hardware and software). In 1999, he joined the University of Picardie "Jules Verne," Amiens, France, as an Associate Professor of electrical engineering. In September 2004, he joined the IUT of Cachan, University of Paris XI, as an Associate Professor of Electrical Engineering. He is with the Laboratoire de Génie Electrique de Paris. His current areas of research include advanced control techniques and diagnosis in the field of ac drives.

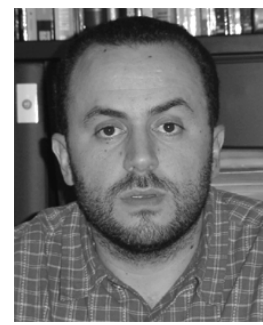

Mohamed El Hachemi Benbouzid (S'92-M'94-SM'98) was born in Batna, Algeria, in 1968. He received the B.Sc. degree in electrical engineering from the Electrical Engineering Institute, Batna University, Batna, Algeria, in 1990, the M.Sc. and Ph.D. degrees in electrical and computer engineering from the $\mathrm{Na}$ tional Polytechnic Institute of Grenoble, Grenoble, France, in 1991 and 1994, respectively, and the Habilitation à Diriger des Recherches degree from the University of Picardie "Jules Verne," Amiens, France, in 2000.

After graduation, he joined the University of Picardie "Jules Verne," where he is an Associate Professor of Electrical and Computer Engineering in the Professional Institute of Amiens, Amiens, France. In September 2004, he joined the IUT of Brest, University of West Brittany, as a Full Professor of Electrical Engineering. His current research interests include electric machines and drives control and diagnosis.

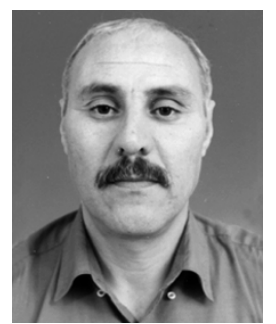

Abdessalam Makouf was born in Batna, Algeria, in 1958. He received the B.Sc. degree in electrical engineering from the National Polytechnic School of Algiers, Algiers, Algeria, in 1983, the M.Sc. degree in electrical engineering from the University of Contantine, Constantine, Algeria, in 1993, and the Ph.D degree in engineering from the University of Batna, Batna, Algeria, in 2003.

After graduation, he joined the University of Batna, where he is an Associate Professor in the Electrical Engineering Institute. 